\title{
Importancia y situación actual de la accesibilidad web para el turismo accesible
}

\author{
Gabriel Fontanet Nadal ${ }^{i}$ \\ Jaime Jaume Mayolii \\ Universidad de las Islas Baleares (España)
}

\begin{abstract}
Resumen: El Turismo Accesible es una modalidad Turismo dirigida a personas que presentan algún tipo de discapacidad. Hace referencia a la eliminación de barreras que impiden o dificultan la práctica del Turismo. Las iniciativas de Turismo Accesible deberían referirse tanto a la accesibilidad física como a la accesibilidad a los sitios web. Se define la Accesibilidad Web como la capacidad de una página web de permitir que personas con discapacidad puedan acceder a sus contenidos. El W3C es un organismo que ha definido normas tendentes a mejorar la accesibilidad web. En el estudio se realiza un análisis de la Accesibilidad Web a webs de contenido turístico. Con ello podremos determinar si el Turismo Accesible también tiene en consideración el componente tecnológico.
\end{abstract}

Palabras clave: Turismo; Hostelería; Turismo accesible; Accesibilidad web; Triple A.

Title: Importance and current status of web accessibility for accessible tourism

\begin{abstract}
Accesible Tourism is a kind of Tourism that is specially dedicated to disabled people. This Tourism refers to the removal of physical elements that difficult the disabled people mobility at the destination. The Accesible Tourism should take care of both physical and web accessibility. The Web Accessibility of a web is defined as the capability this web to be accessed by people with any kind of disability. Some organizations generate rules to improve web accessibility. An analysis of Web Accessibility in Tourist Web Sites is shown at this document.
\end{abstract}

Keywords: Tourism, Hospitality, Tourism accessible, web accessibility, Triple A

i Profesor Titular de universidad del Departamento de Ciencias Matemáticas e Informática de la UIB. Laboratorio de Tecnologías de la Información y Multimedia (LTIM).E-mail: gfontanet@uib.es

ii Escuela de Hotelería de las Islas Baleares (EHIB). Departamento de Ciencias Matemáticas e Informática de la UIB. Laboratorio de Tecnologías de la Información y Multimedia (LTIM). E-mail: jaume.jaume@uib.es 


\section{Introducción}

Las estadísticas de comercio electrónico demuestran que los bienes y servicios más comprados por Internet están relacionados con el ocio y el turismo. En 2008, el $48,8 \%$ de personas de España que adquirieron bienes y servicios por Internet lo hicieron comprando billetes de transporte, el 36,5\% comprado entradas a espectáculos y el $35,3 \%$ en reservas de alojamientos turísticos (AECEM, 2008). Las reservas de productos y servicios turísticos por Internet han aumentado considerablemente durante los últimos años. Durante el mes de enero de 2009 , el $65,5 \%$ de los turistas españoles reservó viajes por Internet, mientras que sólo el 34,5\% lo hicieron a las agencias de viajes tradicionales (HOSTELTUR, 2009). De las afirmaciones anteriores podemos concluir que los servicios Web son fundamentales en la venta de productos turísticos (Molina \& Cánoves, 2010).

Por otra parte, en España un 10\% de la población tiene algún tipo de discapacidad reconocida oficialmente. En Europa había, en 1996, más de 50 millones de personas discapacitadas (ONCE, 2008; Lindon, 2007; IMSERSO, 2009, Marcos \& González, 2003). Todas estas personas son turistas potenciales que deberían poder aprovecharse de la oportunidad de comprar productos turísticos a través de Internet.

En el mundo de la Web, la eliminación de barreras a la discapacidad se llama Accesibilidad Web. Un organismo internacional, denominado W3C (World Wide Web Consortium), ha creado un conjunto de recomendaciones y normas que deberían seguir las páginas web para ser accesibles para personas con algún tipo de discapacidad. En este sentido se han definido varios niveles de accesibilidad, siendo el nivel AAA el nivel máximo de accesibilidad. Ahora bien, actualmente, la mayoría de los sitios Web presentan barreras de accesibilidad, que dificultan o imposibilitan la utilización de la Web para muchas personas con discapacidad (Chisholm et al, 1999; Caldwell et al, 2008).

En el estudio que se presenta se pretende analizar la situación actual de la accesibilidad web en páginas web relacionadas con el sector del Turismo.

\section{Base teórica}

\section{Esquema de la comunicación}

El modelo clásico de la comunicación humana descrito por Jakobson (Jakobson, 1975) incluye cuatro componentes fundamentales (véase figura 1):

- Emisor: hace referencia a la persona que emite el mensaje.

- Receptor: hace referencia a la persona que recibe el mensaje.

- Mensaje: hace referencia a la información que se quiere hacer llegar al receptor.

- Canal de comunicación: se refiere al sistema de transmisión a través del cual el mensaje es transmitido.

- Código: se refiere al código o lenguaje utilizado por el emisor para general el mensaje. Para una correcta comprensión del mensaje, el código debe ser conocido también por el receptor.

- Contexto: hace referencia a las circunstancias externas que rodean al mensaje y que pueden influir en su interpretación (por ejemplo, gestos del propio emisor).

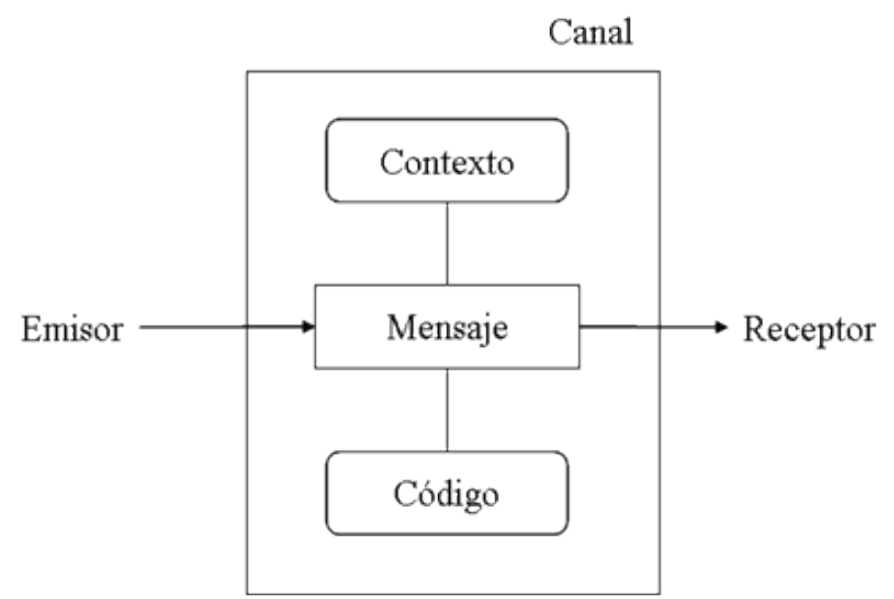

Figura 1. Modelo clásico de comunicación humana (Jakobson, 1975)

Cuando se habla de utilización de Internet en Turismo entonces el emisor es un proveedor de servicios turísticos, el receptor es un turista y el mensaje es la información sobre el producto turístico que se quiere vender.

En el caso de las comunicaciones a través de Internet el canal de comunicación está basado en Tecnologías de la Información y las Comunicaciones. Entonces se trata de una CMC o Computer-Mediated Communication (Connolly, 1996, Ruiz, 2003).

En un proceso comunicativo pueden aparecer problemas que impidan que el receptor pueda acceder al contenido del mensaje. Dichos problemas se denominan, genéricamente, interferencias o ruidos. Algunos ejemplos pueden ser la existencia de diferencias entre emisor y receptor (niveles educativos o culturales) o bien obstáculos entre emisor y receptor (malas interpretaciones o falta de confianza), entre otros (Ruiz, 2003).

En el caso de una CMC, las principales interferencias que se producen son:

- El código impide la comprensión del mensaje a causa de una baja formación técnica para comprender el tipo de lenguaje que se utiliza en la CMC. Este tipo 
de interferencias se conocen como brecha digital (Serrano \& Martínez, 2003; Volkov, 2003).

- El código impide la comprensión del mensaje a causa de problemas de comprensión del receptor. Puede ser debido a problemas de comprensión del lenguaje en general o a problemas de comprensión del tipo de lenguaje utilizado en una CMC (Volkov, 2003).

- El receptor es capaz de entender el contenido del mensaje pero existen diferencias culturales que impiden la correcta comprensión del mismo. Este tipo de interferencias se deben a problemas de Comunicación Intercultural (Andrews \& Jaume, 2010).

- El canal de comunicación impide que personas que padecen algún tipo de discapacidad puedan acceder ción. Durante el siglo XX la población española se ha multiplicado por 2,4, mientras que la población de 65 años o más se ha multiplicado por 8 (IMSERSO, 2009). De este modo, el año 2008, el 16,7\% de la población española tenía 65 años o más. La población mayor tiene una mayor incidencia de diversos tipos de discapacidad. Las estadísticas indican que el $26 \%$ de la población de 65 a 79 años tiene algún tipo de discapacidad, porcentaje que aumenta al 50\% en personas de 80 o más años (ONCE, 2008).

A nivel europeo (Unión Europea) los países con mayores porcentajes de discapacidad son Alemania y Reino Unido, que suman más de un $45 \%$ de la población discapacitada europea (Marcos \& González, 2003). En al contenido del mensaje. Se trata de un problema de Accesibilidad Web (Chisholm et al, 1999; Caldwell et al, 2008).

La accesibilidad Web significa que personas con algún tipo de discapacidad deben poder hacer uso de la Web. En concreto, Accesibilidad Web hace referencia a un diseño Web que debe permitir que estas personas puedan percibir, entender, navegar e interactuar con la Web.

\section{Informe de Discapacidad}

La accesibilidad Web engloba muchos tipos de discapacidades, incluyendo problemas visuales, auditivos, físicos, cognitivos, neurológicos y del habla. Entonces lo primero que debe considerarse es el colectivo que se ve afectado por el problema:

- Según diversos estudios, (ONCE, 2008) y

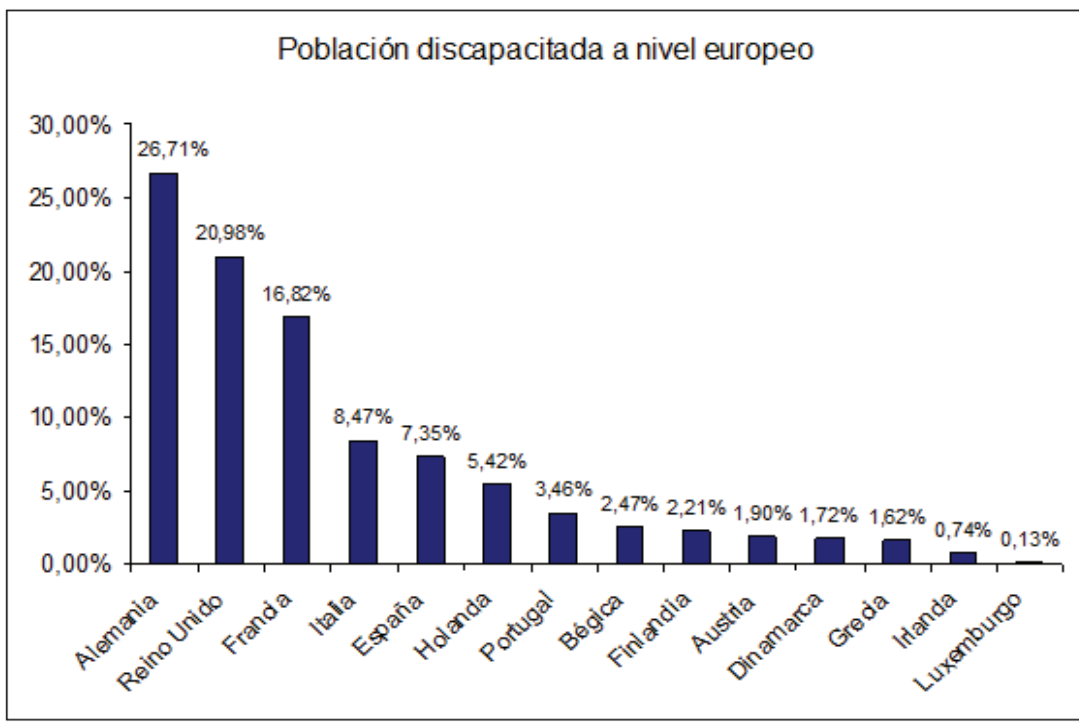
(Lindon, 2007), en España había, en 1999, más de 3.500.000 personas con algún tipo de discapacidad reconocida oficialmente (que supone aproximadamente el $10 \%$ de la población total española). Además, como se puede ver en la tabla 1, la mayoría de discapacitados tienen entre 45 y 79 años (en total son el $60 \%$ del total de la población con discapacidad).

- Existe un envejecimiento progresivo de la pobla-

Figura 2. Porcentajes nacionales de población discapacitada, sobre el total de la Unión Europea (Marcos \& González, 2003)

la figura 2 puede verse un gráfico comparativo del porcentaje de discapacidad en algunos países, sobre el total de población discapacitada europea.

Respecto de los tipos de discapacidad de acceso a las nuevas tecnologías, éstas pueden se pueden clasificar en (Fernández, 2009, Domínguez \& Fraiz, 2009):

- Físicas: Afectan a la movilidad o la captación de in-

\begin{tabular}{lrrrrrr} 
Edad & Hombres & Mujeres & Total & Hombres & Mujeres & Total \\
Menos de 6 & 24723 & 24853 & 49576 & $1,68 \%$ & $1,21 \%$ & $1,41 \%$ \\
\hline 16 & 43051 & 37211 & 80262 & $2,92 \%$ & $1,81 \%$ & $2,27 \%$ \\
\hline 44 & 291736 & 215782 & 507518 & $19.81 \%$ & $10.50 \%$ & $14.38 \%$ \\
\hline 64 & 379652 & 438561 & 818213 & $25.77 \%$ & $21.34 \%$ & $23.19 \%$ \\
\hline 79 & 502396 & 818137 & 1320533 & $34.11 \%$ & $39.81 \%$ & $37.43 \%$ \\
\hline 80 o más & 231413 & 520707 & 752120 & $15.71 \%$ & $25.34 \%$ & $21.32 \%$ \\
\hline & 1472971 & 2055251 & 3528222 & & &
\end{tabular}
formaciones a través de los sentidos.

- Intelectuales: Afectan a la capacidad de comprensión de la información.

- Tecnológicas: Se refieren a problemas para acceder a la información debido al sistema empleado para acceder a

Tabla 1. Personas con discapacidad en España, por edad y sexo (Lindon, 2007) la información. Pueden ser 
conexiones lentas a Internet, falta de instalación de plugins del navegador, etc.

Según la temporalidad, las discapacidades pueden ser (Fernández, 2009):

- Temporales: Afectan de manera temporal, como un tener una fractura.

- Definitivas: La persona sufre la discapacidad de manera definitiva, sin posibilidad de recuperación de la capacidad perdida.

No existe ninguna categorización universal de la discapacidad, aunque hay esfuerzos internacionales hacia este objetivo. La terminología comúnmente utilizada en la discapacidad varía de país a país. Algunas personas pueden tener limitaciones de funcionamiento sensorial, física o cognitiva, que, sin ser declaradas oficialmente como discapacitadas, pueden afectar el acceso a la web. Las discapacidades pueden incluir lesiones relacionadas con el envejecimiento y pueden ser temporales o crónicas. En este sentido, el número y la severidad de las limitaciones tienden a aumentar con la edad, y pueden incluir cambios en la visión, la audición, la memoria o la función motora (Fernández, 2009).

\section{Turismo Accesible}

En este sentido se ha define el Turismo Accesible, que hace referencia a la práctica turística que está orientada a las personas con discapacidad, que consiste en asegurar las condiciones necesarias para que una persona que presenta alguna discapacidad pueda hacer Turismo (OMT, 2009).

LA OMT define el Turismo Accesible como "aquel que pretende facilitar el acceso de las personas con discapacidad a los servicios turísticos”. Es decir, posibilita que las personas con discapacidad permanente o temporal tengan las condiciones adecuadas de seguridad y autonomía para el desarrollo de sus actividades en lugares físicos, a la prestación de servicios y los sistemas de comunicación (OMT, 2009).

Hay iniciativas para impulsar el Turismo Accesible. A nivel internacional podemos destacar acciones por organismos como la ENAT (European Network for Accesible Tourism), con la celebración de Congresos relacionados dicha modalidad de turismo (ENAT, junio 2010). A nivel nacional podemos destacar el proyecto DISUIPA (http://www.daedalus.es/), del Ministerio de Industria, Turismo y Comercio del Gobierno de España, que pretende desarrollar una plataforma universal de acceso a Internet a través de redes inalámbricas de acceso público. A nivel local podemos destacar iniciativas municipales como la del Ayuntamiento de Calvià, en Mallorca (España), que ha desarrollado el Plan de Turismo Accesible de Calvià (Calvià, 2010).

\section{Accesibilidad Web}

La W3C es un organismo internacional que desarrolla estándares tendentes a asegurar el crecimiento de la Web a largo plazo. El W3C definió la WAI (Web Accessibility Initiative), una iniciativa para mejorar el acceso a la Web de personas que presentan algún tipo de discapacidad (http://www.w3c.org).

El W3C también ha desarrollado un conjunto de guías de diseño para conseguir páginas web accesibles. En 1999 se desarrollaron los estándares de la WCAG 1.0 (Web Content Accessibility Guide) que fue la primera guía de diseño web accesible para programadores. En 2008, con los cambios tecnológicos de la última década en las tecnologías Web, dictó una segunda versión de la normativa y guía de diseño, que se llamó WCAG 2.0. A continuación pasamos a hacer un pequeño resumen de la normativa de la WCAG 2.0. Para un estudio más detallado se recomienda la lectura de la bibliografía recomendada en (Chisholm et al, 1999; Caldwell et al, 2008)

La normativa de la WCAG 2.0 está organizada en un conjunto de niveles de análisis, que se pasan a describir brevemente (Caldwell et al, 2008):

- Principios: Son las bases a que se refiere cada una de las recomendaciones de la WCAG. En este sentido, podemos decir que una web puede ser "Perceptiva" (el usuario debe poder acceder a la información), "Operable" (debe poder navegar en la web), "Comprensible" (debe entenderse la información que hay contenida) y "Robusta" (la accesibilidad no debe depender de la tecnología que se emplee para acceder a la web).

- Criterios de Éxito o Puntos de Control: Se refiere a los criterios a seguir para alcanzar los Principios de accesibilidad comentados anteriormente. El objetivo de la consecución de los Criterios de Éxito o Puntos de Control es alcanzar los diversos niveles de accesibilidad que se definen: A, AA y AAA

- Técnicas de consecución de los Criterios de Éxito o Puntos de Control: Son las técnicas que se recomiendan para conseguir el éxito en la programación de HTML que supere los Puntos de Control.

La WCAG 2.0 (Caldwell et al, 2008) vincula cada uno de los Puntos de Control con un nivel de accesibilidad. Así, los hay que son necesarios para alcanzar un mínimo de accesibilidad, que son los que estarían vinculados al nivel A (nivel mínimo).

- Nivel A: Se alcanza cuando se cumplen todos los Puntos de Control que están relacionados con el nivel A. Es el nivel mínimo de accesibilidad y no lograrlo hará que un grupo de usuarios no podrá acceder al contenido de la web. 
- Nivel AA: Se alcanza cuando se cumplen todos los Puntos de Control que están relacionados con los niveles A y AA. Es el nivel intermedio de accesibilidad y no lograrlo hará que un grupo de usuarios tendrá muchas dificultades para acceder al contenido web.

- Nivel AAA: Se alcanza cuando se cumplen todos los Puntos de Control que están relacionados con los niveles A, AA y AAA. Es el nivel máximo de accesibilidad y no lograrlo hará que un grupo de usuarios tendrá algunas dificultades para acceder al contenido web. Una web que alcanza el nivel AAA puede ser accedida por todos los usuarios

\section{Legislación sobre accesibilidad}

Existen normas que establecen las condiciones que deben darse para que las personas con algún tipo de discapacidad puedan acceder a los diversos lugares físicos, públicos y privados. La mayoría de esta normativa hace referencia a la accesibilidad física.

En el caso de la accesibilidad Web existen normas legales, como la Ley 51/2003, de 2 de diciembre, de Igualdad de Oportunidad, No Discriminación y Accesibilidad Universal de las Personas con Discapacidad o la Ley 34/2002, de 11 de julio, de Servicios de la Sociedad de la Información y de Comercio Electrónico (LSSICE).

Una de las más importantes es la Ley 56/2007, de 28 de diciembre, de Medidas de Impulso de la Sociedad de la Información. En ella, podemos ver los siguientes artículos:

- Dieciocho: «A partir del 31 de diciembre de 2008, las páginas de Internet de las administraciones públicas deben satisfacer, como mínimo, el nivel medio de los criterios de accesibilidad al contenido generalmente reconocidos. Excepcionalmente, esta obligación no es aplicable cuando una funcionalidad o servicio no disponga de una solución tecnológica que permita su accesibilidad. "

- Diecinueve: «Las administraciones públicas deben exigir que tanto las páginas de Internet, el diseño o el mantenimiento de las que financien total o parcialmente, como las páginas de Internet de entidades y empresas que se encarguen de gestionar servicios públicos, apliquen los criterios de accesibilidad antes mencionados. En particular, es obligatorio lo que expresa este apartado para las páginas de Internet y sus contenidos de los centros públicos educativos, de formación y universitarios, así como de los centros privados que obtengan financiación pública. Las páginas de Internet de las administraciones públicas deben ofrecer al usuario información sobre su nivel de accesibilidad y facilitar un sistema de contacto para que puedan transmitir las dificultades de acce- so al contenido de las páginas de Internet o formular cualquier queja, consulta o sugerencia de mejora. “

- Veinte: "Las administraciones públicas deben promover medidas de sensibilización, educación y formación sobre accesibilidad con el objeto de promover que los titulares de otras páginas de Internet incorporen progresivamente los criterios de accesibilidad. Los incumplimientos de las obligaciones de accesibilidad establecidas en esta disposición adicional estarán sometidos al régimen de infracciones y sanciones vigente en materia de igualdad de oportunidades, no discriminación y accesibilidad universal de las personas con discapacidad. Las páginas de Internet de las empresas que presten servicios al público en general de una trascendencia económica especial, sometidas a la obligación que establece el artículo 2 de la Ley 56/2007, de Medidas de Impulso de la Sociedad de la Información, deben satisfacer a partir de 31 de Diciembre de 2008, como mínimo, el nivel medio en los criterios de accesibilidad al contenido generalmente reconocidos. De manera excepcional, esta obligación no será aplicable cuando una funcionalidad o servicio no disponga de una solución tecnológica que permita su accesibilidad"

Según esta norma, dado que las empresas turísticas prestan servicios al público que tienen una trascendencia económica especialmente importante, deberían cumplir el nivel medio de accesibilidad web, que es el nivel AA de la norma de la WAI (Fernández, 2009).

\section{Beneficios de la mejora de la accesibilidad Web}

Mejorar la accesibilidad de las páginas web ofrece todo un conjunto de beneficios. Los destinatarios principales son las personas con discapacidad, pero no sólo son éstas las beneficiadas por la accesibilidad. Una mejora de la accesibilidad de un sitio web mediante la conformidad con las WCAG mejora la cuota de mercado y la audiencia alcanzada por el sitio web (Serrano, 2009).

Se puede considerar que la accesibilidad proporciona capacidad para utilizar un sistema de información a aquellos usuarios que utilicen cualquier dispositivo para acceder a Internet como, por ejemplo, teléfonos móviles, tablets, etc.

Por otro lado, la adopción de las recomendaciones de las WCAG demuestra también un alto grado de compromiso social y con la igualdad de acceso a la información y servicios.

Los beneficios de la accesibilidad web se pueden resumir en (Fraiz et al, 2008, Serrano, 2009):

- Incremento de la cuota de mercado y alcance de la audiencia: Según diversos estudios, la proporción de población con discapacidades puede superar el 20\% 
en algunas poblaciones. Una parte significativa de estas personas con discapacidades puede beneficiarse de sitios Web conformes con las WCAG.

- Mejora de la usabilidad para los visitantes con discapacidades y para aquellos sin limitación destacable debido a la mejora que se produce en la navegación (más clara y consistente) y la independencia del dispositivo (PC, tablets, móvil). Este beneficio se constata en funcionalidades basadas en dispositivos móviles (Jiménez, 2010).

- Soporte para niveles de baja alfabetización: El seguimiento de las recomendaciones de las WCAG permite facilitar la comprensión del contenido del sitio web tanto a los usuarios con bajo nivel de alfabetización como a aquellas personas poco acostumbradas al lenguaje propio de las páginas web.

- Asistencia al acceso de los usuarios con reducido ancho de banda: Una estrategia que permite el crecimiento del mercado es proporcionar contenido alternativo apropiado para conexiones de bajo ancho de banda.

- Reducción del mantenimiento del sitio: Los costes de desarrollo y mantenimiento se ven reducidos por la aplicación de técnicas de diseño como las propuestas por las WCAG.

- Reutilización de contenido: La aplicación de prácticas de independencia de dispositivo mejora la capacidad de reutilizar el contenido para utilizarlo con otros dispositivos preparados para la Web como teléfonos WAP o PDA (Jiménez, 2010).

- Demostrar responsabilidad social: Incrementar la accesibilidad de los sitios web y servicios en línea a un rango más amplio de personas con discapacidades y otros miembros con desventajas de la comunidad refuerza la actitud socialmente responsable de la organización. Las cifras de personas con alguna discapacidad son significativas en todos los países y representan una proporción influyente de la población. A este hecho hay que añadir el fenómeno de aumento gradual de personas de la tercera edad, sector de población que tiene una mayor incidencia de discapacidades.

\section{Análisis de la accesibilidad Web}

Los errores en puntos de control de accesibilidad web se pueden clasificar en dos tipos (Serrano, 2009):

- Aquellos que se pueden detectar de forma automática, mediante un programa.

- Aquellos que sólo se pueden detectar de forma manual, con la intervención de personal especialista en temas de accesibilidad.

A continuación se presentan los puntos de control que se pueden analizar de forma automática, junto al nivel de accesibilidad (A, AA, AAA) al que pertenecen y referidos a la normativa de la WCAG 2.0 (Caldwell et al, 2008).

Puntos de Control de nivel 1 (nivel A de Accesibilidad Web):

- 1.1.1 Contenido No textual: Todo contenido no textual debe tener un texto alternativo que el describa. Por ejemplo, las imágenes deben tener una descripción de la imagen dentro del atributo ALT.

- 1.3.1 Información y relaciones: Debe haber información alternativa textual sobre los elementos que se deben introducir por teclado (entradas de datos). Por ejemplo, la mayoría de elementos de tipo INPUT deben tener una etiqueta de tipo LABEL.

- 2.1.1 Teclado: Todas las funcionalidades se tienen que poder realizar a través del teclado y sin tener unos condicionantes de tiempo asociados a las teclas de control.

- 2.4.4 Propósito del hipervínculo: Cada uno de los enlaces debe tener información sobre la página destino que se visitará al hacer clic. Esta información debe ser en forma de texto escrito en la página web o en forma de imagen y la correspondiente descripción de la misma.

- 3.1.1 Idioma de la página web: Al principio del documento debe estar especificado el idioma de la web. Se trata de especificar la cláusula LANGUAGE dentro de la cabecera del documento HTML, ASP, o similares.

- 4.1.1 Duplicidades: Se ha de comprobar que no se tienen duplicidades en las etiquetas, descripciones, nombres de elementos de entrada de datos y otros elementos de la página web.

Puntos de Control de nivel 2 (nivel AA de Accesibilidad Web):

- 1.4.4 Tamaño del texto: El texto de la página web debe poder redimensionar sin necesidad de tecnologías adicionales. En particular, debe poder aumentar hasta un $200 \%$, sin pérdida de contenidos ni funcionalidades.

- 2.4.7 Acceso del teclado: Se debe comprobar que todas las funcionalidades se pueden acceder a través de teclado. Se diferencia del 2.1.1 por condicionantes temporales.

Puntos de Control de nivel 3 (nivel AAA de Accesibilidad Web):

- 2.2.4 Interrupciones: Se ha de comprobar que no hay interrupciones ejecución del código. Por ejemplo, se tienen que evitar las cláusulas que provocan que se cargue otra página web de forma automática, como por ejemplo las cláusulas que provocan una redirec- 
cion a otra página web después de un tiempo determinado.

- 2.4.9 Propósito del hipervínculo: Se ha de comprobar que siempre que exista un enlace con texto poco descriptivo como "haga clic aquî" o "más información” se tiene información adicional para contexto.

- 2.4.10 Encabezados de sección: Comprobar que el documento está dividido en secciones, con marcas HTML para identificar cada una de las secciones.

- 3.2.5 Cambios a petición: Se trata de comprobar que los cambios de contenidos se producen sólo a petición del usuario o que hay algún sistema para desactivar el proceso de cambios automáticos.

El documento WCAG 2.0 da un conjunto de recomendaciones y procedimientos para eliminar los errores que se producen en los Puntos de Control (Caldwell et al, 2008).

Existen herramientas que permiten hacer revisiones de cumplimiento de los Puntos de Control automáticos. Son instrumentos que permiten la automatización del proceso de evaluación de la accesibilidad de una página o sitio web, valorando su nivel de conformidad de acuerdo a unas determinadas pautas (definidas por el W3C). Es importante destacar que las pruebas de evaluación se basan en un método automático, por lo tanto, los resultados del análisis realizado por las herramientas son complementarios, nunca sustitutivos del análisis manual. Las herramientas automáticas permiten hacer una primera aproximación. Ahora bien, podemos asegurar que los errores que se detectan de manera automática se detectarían también de forma manual. En cambio, puede haber errores que sólo se pueden detectar de forma manual y no automática. Se trata, por tanto, de aproximaciones. En cualquier caso, podemos asegurar que si un Sitio Web no supera un determinado nivel de accessibilidad web de manera automática, no lo superará de manera manual (Serrano, 2009).

Un ejemplo de dichas herramientas de evaluación automática la encontramos en el Test de Accesibilidad Web (TAW), desarrollado por la Fundación CTIC (http:// www.tawdis.net). Sirve de ayuda para desarrolladores de páginas web (García, 2006).

\section{Descripción del estudio}

\section{Objetivos}

Los principales objetivos que se han planteado son:

- Analizar el grado de cumplimiento por parte de los Sitios Web de contenido Turístico de las normas de Accesibilidad Web que recomienda la WAI. Se trata de comprobar si los Sitios Web de contenido turístico siguen las pautas de diseño web que permiten alcan- zar el nivel de accesibilidad que se recomienda en la Ley de Medidas de Impulso de la Sociedad de la Información

- Revisar la evolución que se ha producido en la accesibilidad web a partir de estudios anteriores del mismo autor.

- Realizar una comparación entre los niveles de accesibilidad que se alcanzan con las dos normas que ha creado el W3C, la WCAG 1.0 y la WCAG 2.0

\section{Metodología}

Para realizar el estudio se ha analizado la página principal de 102 sitios web relacionados con el sector turístico (40 cadenas hoteleras españolas, 49 hoteles de 4 ó 5 estrellas de la isla de Mallorca y 13 compañías aéreas). Los datos se han tomado durante los meses de abril y mayo de 2010 y se ha utilizado la aplicación TAW para determinar el nivel de accesiblidad web desde el punto de vista automático que se alcanza en cada uno de los sitios web.

\section{Puntos de Verificación i de Control analizados}

Los Puntos de Verificación (WCAG 1.0) y los Puntos de Control (WCAG 2.0) analizados son los que se pueden revisar de manera automática, que son, precisamente, los que se retornan en el código fuente de TAW (Fernández, 2009, García, 2006; TAW, junio 2010).

\section{Resultados}

\section{Análisis de la WCAG 1.0}

En la tabla 2 se muestran el total y el porcentaje de páginas web que han alcanzado cada uno de los niveles de Accesibilidad. La mayoría de sitios web analizados no cumplen ninguna de las normas de accesibilidad que permitirían alcanzar el nivel A (el mínimo). Así, el 80,4\% no permiten ningún tipo de accesibilidad. Este porcentaje es superior a las páginas web de las cadenas hoteleras $(82,5 \%)$ y las compañías aéreas $(84,6 \%)$. En la muestra total, sólo un 17,6\% alcanza el nivel A y sólo 2 sitios web alcanzan el nivel AAA (1,9\%).

En estudios anteriores, (Jaume \& Batle, 2006 y 2007), se demuestra que los niveles de accesibilidad web, según la norma WCAG 1.0, en sitios web de contenidos turístico era del 20\% para el nivel A y del $0 \%$ para los niveles AA y AAA (con una muestra de 60 sitios web). Se puede ver el resultado del análisis en la tabla 3.

Si se comparan los datos anteriores al estudio que se ha hecho en 2010 (tabla 2) podemos ver que el porcentaje de páginas web accesibles no ha mejorado significativamente desde 2006 (tabla 3). En la figura 3 se puede apreciar un gráfico comparativo. 
Total de sitios web por nivel

$\%$ de sitios web per nivel

Categoría Ninguno A AA AAA Total Ninguno A AA AAA

$\begin{array}{llllllllll}\text { Cadena } & 33 & 6 & 0 & 1 & 40 & 82,5 \% & 15,0 \% & 0,0 \% & 2,5 \%\end{array}$

\begin{tabular}{cccccccccc}
\hline Airlines & 11 & 2 & 0 & 0 & 13 & $84,6 \%$ & $15,4 \%$ & $0,0 \%$ & $0,0 \%$ \\
\hline Hoteles & 38 & 10 & 0 & 1 & 49 & $77,6 \%$ & $20,4 \%$ & $0,0 \%$ & $2,0 \%$ \\
\hline Muestra total & 82 & 18 & 0 & 2 & 102 & $80,4 \%$ & $17,6 \%$ & $0,0 \%$ & $1,9 \%$
\end{tabular}

Tabla 2. Total y porcentaje de sitios web por nivel de accesibilidad. Elaboración propia.

Total de sitios web por nivel

$\%$ de sitiosweb per nivel

Categoría Ninguno A AA AAA Total Ninguno A AA AAA

\begin{tabular}{cccccccccc} 
Cadena & 18 & 2 & 0 & 0 & 20 & $90,0 \%$ & $10,0 \%$ & $0,0 \%$ & $0,0 \%$ \\
\hline Hoteles & 30 & 10 & 0 & 0 & 40 & $75,0 \%$ & $25,0 \%$ & $0,0 \%$ & $0,0 \%$ \\
\hline Muestra total & 48 & 12 & 0 & 0 & 60 & $80,0 \%$ & $20,0 \%$ & $0,0 \%$ & $0.0 \%$
\end{tabular}

Tabla 3. Niveles de Accesibilidad Web que se alcanzaba en Sitios Web de Cadenas Hoteleras y Hoteles en 2006, según la norma WCAG 1.0 (Jaume\& Batle, 2006).

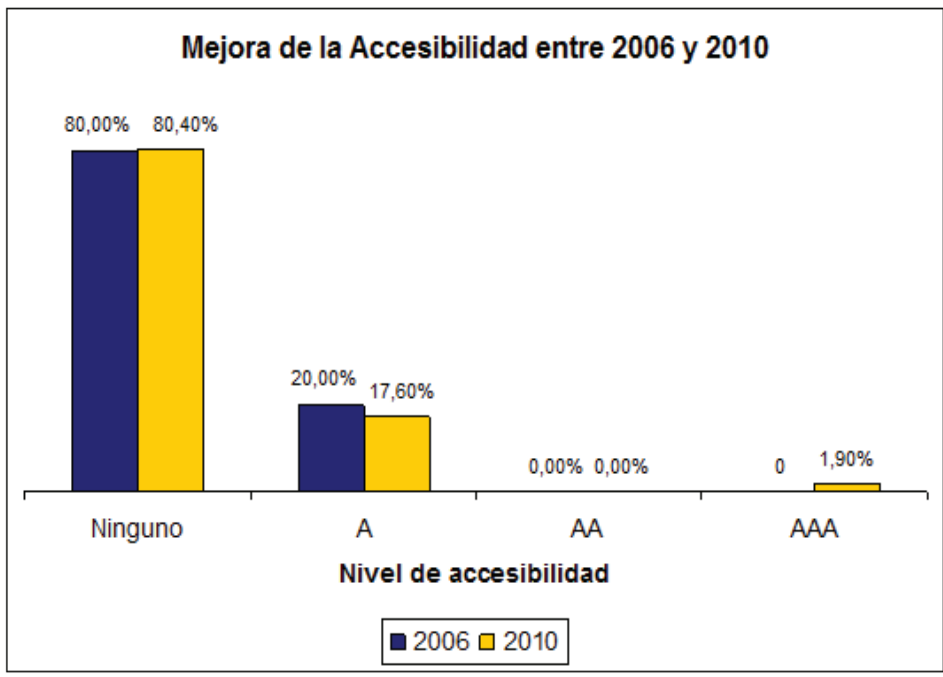

Figura 3. Evolución de la Accesibilidad Web entre 2006 y 2010. Elaboración propia.

\begin{tabular}{crrrr}
\hline \multicolumn{5}{c}{$\%$ de páginas que tienen errores, por prioridady el Principio } \\
Nive & Perceptible & Operable & Comprensible & Robusta \\
A & $96,8 \%$ & $67,2 \%$ & $88,5 \%$ & $68,7 \%$ \\
\hline AA & $69,8 \%$ & $1,1 \%$ & - & - \\
\hline AAA & - & $85,6 \%$ & $3,2 \%$ & - \\
\hline
\end{tabular}

Tabla 4. Análisis WCAG 2.0 de la Accesibilidad Web Fuente TAWDIS, elaboración propia.

\begin{tabular}{crrrr} 
Nivel & Perceptible & Operable & Comprensible & Robusta \\
Ninguno & $96,8 \%$ & $67,2 \%$ & $88,5 \%$ & $68,7 \%$ \\
\hline A & $1,4 \%$ & $0,0 \%$ & $11,5 \%$ & $31,3 \%$ \\
\hline AA & $1,7 \%$ & $27,9 \%$ & $0,0 \%$ & $0,0 \%$ \\
\hline AAA & $0,0 \%$ & $4,9 \%$ & $0,0 \%$ & $0,0 \%$ \\
\hline
\end{tabular}

Tabla 5. Niveles de Accesibilidad Web que se alcanzan, por Principio.

\section{Análisis de la WCAG 2.0}

Se empleó la aplicación TAW para determinar el nivel de accesibilidad según la norma de la WCAG 2.0, analizando los Puntos de Control que se pueden detectar de manera automática.

El análisis se ha realizado desde dos puntos de vista:

- Análisis del porcentaje de aparición de cada una de los errores.

- Análisis de los niveles de accesibilidad que alcanzan los sitios web.

En la tabla 4 se puede apreciar el resultado final del análisis del incumplimiento de Puntos de Control, según los Principios de la WCAG 2.0, sobre el total de la muestra. En ella se puede detectar que se producen errores en todos los niveles de accesibilidad de todos los Principios de Accesibilidad. Así, el 96,8\% de páginas web presentan errores de perceptibilidad de tipo A, el 67,2\% de Operabilidad, el 88,5\% de comprensibilidad y el 68,7\% de Robustez.

Con estos datos, los niveles de Accesibilidad Web que se alcanzan pueden verse en la tabla 5 . Un porcentaje superior al $65 \%$ de páginas no alcanza el nivel mínimo de Accesibilidad. Los mejores resultados corresponden al nivel A en los Principios de Comprensibilidad (11,5\%) y Robustez (31,3\%) y al nivel AA en el Principio de Operabilidad (27,9\%).

\section{Conclusiones e implicaciones del estudio}

Algunas de las conclusiones a las que podemos llegar del documento anterior son:

- A pesar de la normativa legal (Ley 56/2007 de Medidas de Impulso de la Sociedad de la Información) con recomendaciones y órdenes de mejora de la accesibilidad, podemos asegurar, sobre la muestra considerada, que los sitios web de contenido turístico no siguen las pautas de diseño web de la WAI que permiten alcanzar el nivel de accesibilidad AA. Esta falta de Accesibilidad provoca que los turistas con discapacidad no puedan disfrutar de un auténtico y completo Turismo Accesible, puesto que existen barreras para realizar la primera acción que se realiza en la preparación de un viaje turístico, que es un acceso a Internet para informarse del destino o para adquirir un producto turístico.

- El hecho de no disponer de una mejor Accesibilidad Web, las organizaciones turísticas pierden una serie de beneficios empresariales de tipo económico y de imagen. En este sentido cabe destacar casos especialmente importantes, como el de las líneas aéreas: algunas tienen su base de negocio por Inter- 
net (como las Low-Cost) y no alcanzan los mínimos de accesibilidad. Es decir, con los niveles actuales, es imposible que algunas personas discapacitadas puedan reservar por sí mismas un viaje en determinadas compañías Low-Cost, con la consiguiente pérdida económica en beneficio de otras compañías.

- Existen iniciativas de Turismo Accesible, a nivel internacional, estatal o local. Dichas iniciativas tienen en cuenta la accesibilidad física en la zona de destino (zona turística o establecimiento turístico). Sin embargo, la mayoría de las iniciativas no tienen en cuenta la Accesibilidad Web. Narbaiza (Narbaiza, 2004) afirma que accesibilidad a medias no es accesibilidad. Por tanto, se podría afirmar que muchas iniciativas de Turismo Accesible que se realizan no son accesibles.

\section{Referencias Bibliográficas}

AECEM Asociación Española de Comercio Electrónico y Márketing Relacional

2008 "Libro Blanco del Comercio Electrónico: Guía Práctica de Comercio Electrónico para PYMES. Año 2008 "

Andrews, R; Jaume, J

2010 "Towards an Intercultural Web Design in Tourist Web Sites". The Fisrt International Conferences on Tourism between China- Spain, March 28-31, 2010, Palma: Editorial Pearson.

Caldwell, B; Cooper, M; Guarino, L; Vanderheiden; G. 2008 "Web Content Accessibility Guidelines (WCAG) 2.0. W3C Recommendation", World Wide Web Consortium (W3C), 11 de desembre de 2008.

Calvià

2010 "Calvià, turismo accesible todo el año". Descripción del proyecto de Turismo Accesible para calivà, Mallorca

Chisholm, W; Vanderheiden, G; Jacobs, I.

1999 "Web Content Accessibility Guidelines (WCAG) 1.0. W3C Recommendation”, World Wide Web Consortium (W3C), 5 de maig de 1999. December 2008.

Connolly, J

1996 International User Interfaces: Problems in Designing the User Interface for Systems Supporting International Human-Human Communication. Edited by Elisa M. Del Galdo \& Jakob Nielsen. Library of Congress, USA.

Domínguez, T; Fraiz, J.A

2009 "Un nuevo desafío: el contenido y la accesibilidad al contenido de las web turísticas españolas", Revista galega de economía, 18(1).
Fernández, M.T.

2009 "Turismo Accesible: importancia de la accesibilidad para el sector turístico", Revista interdisciplinar Entelequia, núm 9, primavera 2009, accesible en http://www.eumed.net/entelequia

Fraiz, J.A; Alén, E; Domínguez, T

2008 "Un nuevo desafío para la Web: el contenido sobre accesibilidad en las Web turísticas oficiales de las Comunidades Autónomas". VII Congreso Nacional de Turismo y Tecnologías de la Información y las Comunicaciones - TURITEC 2008, Málaga, octubre de 2006. Ed: Universidad de Turismo (Universidad de Màlaga).

García, J.

2006 "Test de accesibilidad web (TAW). Una herramienta imprescindible para analizar la accesibilidad de los sitios web". BOLETIC, accesible en http://www. astic.es

\section{HOSTELTUR}

2009 "E-comunicación para el turismo del futuro: Noticias", publicado en www.hosteltur.com el dia 25/02/09

IMSERSO Secretaría General de Política Social (IMSERSO) del Ministerio de Sanidad y Política Social

2009 "Las Personas Mayores en Espanya. Datos estadísticos estatales y por Comunidades Autónomas. Informe 2008". Catálogo General de Publicaciones Oficiales. Impreso por Grafo, SA, 2009.

Jakobson, R

1975 "Ensayos de lingüística general”, Barcelona: Ed. Seix Barral.

Jaume, J; Batle, MM

2006 "Análisis de la Accesibilidad Web en Sitios Web de Hoteleria", VI Congreso Nacional de Turismo y Tecnologías de la Información y las Comunicaciones - TURITEC 2006, Málaga, 18, 19 i 20 d'octubre de 2006. Ed: Universidad de Turismo (Universidad de Màlaga).

Jaume, J; Batle, MM

2007 "Turismo virtual para todos o Accesibilidad a Web turísticos". Congreso Internacional Turismo para Todos ENAT Tourism for All. Organizado por la Fundación ONCE, ENAT (European Network for Accessible Tourism) y la Comisión Europea. Comunitat Valenciana, 21-23 de novembre de 2007

Jiménez, J; Chao, J; Bibiloni, T; Fontanet, G

2010 "Dynamic Generation and Visualization of Customized Touristic Packages" The Fisrt International Conferences on Tourism between China- Spain, March 28-31, 2010, Palma - Spain. Editorial Pearson. Digital 
Lindon, L.

2007 Derechos Humanos y Discapacidad en España. Informe de situación. Fundación ONCE, 2007.

Marcos, D; González, D.

2003 Turismo Accesible. Hacia un Turismo para todos, MAZARS TURISMO, Ministerio de Trabajo y Asuntos Sociales, Madrid: Comité Español de Representantes de Personas con Discapacidad (CERMI). marzo de 2003.

Molina, M; Cánoves, G

2010 "Turismo Accesible, Turismo para Todos: La situación en Cataluña y España”. Cuadernos de Turismo. Universidad de Murcia, España.

Narbaiza, I.

2004 "Accesibilidad a medias no es accesibilidad" No Solo Usabilidad, nº 3, 2004. Accesible en http://wwwnosolousabilidad.com.

OMT Organización Mundial del Turismo WTO-UNWTO

2009 "Panorama del turismo internacional. Edición 2009"; Sección "Datos y cifras" de la OMT; disponible en www.unwto.org ; Edición de 2009

ONCE Fundación ONCE

2008 "Derechos Humanos y Discapacidad en Espanya. Informe de situación”, Ed: Grupo editorial Cinca, SA, 2008.

Ruiz, M.F

2003 “Aplicaciones pedagógicas del informe empresarial en el aula del inglés de los negocios: implementación de recursos discursivos escritos en contextos de especialidad”, Departamento de Filología Inglesa y Románica de la Universidad Jaume I de Castelló.

Serrano, A; Martinez, E

2003 La Brecha Digital: Mitos y Realidades, México: Editorial UABC, .

Serrano, E.

2009 "Herramientas para la evaluación de la accesibilidad Web. Documentación de las Ciencias de la Información 2009", 32: 245-266, Universidad de Alcalá, 2009.

Volkov, N

2003 "La brecha digital, un concepto social con cuatro dimensiones”. Boletín de Política Informàtica, 6.
Recibido:

$23 / 07 / 10$

Reenviado:

$13 / 12 / 10$

Aceptado:

$07 / 01 / 11$

Sometido a evaluación por pares anónimos 